University of Nebraska - Lincoln

DigitalCommons@University of Nebraska - Lincoln

July 1997

\title{
Influence of Dominance Relationships on the Estimation of Dominance Variance with Sire-Dam Subclass Effects
}

\author{
N. Gengler \\ University of Nebraska-Lincoln \\ L. Dale Van Vleck \\ University of Nebraska-Lincoln, dvan-vleck1@unl.edu
}

M. D. MacNeil

Ft. Keogh Livestock and Range Research Laboratory, USDA-ARS, Miles City, MT

I. Misztal

University of Georgia, Athens

F. A. Pariacote

University of Georgia, Athens

Follow this and additional works at: https://digitalcommons.unl.edu/animalscifacpub

Part of the Animal Sciences Commons

Gengler, N.; Van Vleck, L. Dale; MacNeil, M. D.; Misztal, I.; and Pariacote, F. A., "Influence of Dominance Relationships on the Estimation of Dominance Variance with Sire-Dam Subclass Effects" (1997). Faculty Papers and Publications in Animal Science. 268.

https://digitalcommons.unl.edu/animalscifacpub/268

This Article is brought to you for free and open access by the Animal Science Department at DigitalCommons@University of Nebraska - Lincoln. It has been accepted for inclusion in Faculty Papers and Publications in Animal Science by an authorized administrator of DigitalCommons@University of Nebraska - Lincoln. 


\title{
Influence of Dominance Relationships on the Estimation of Dominance Variance with Sire-Dam Subclass Effects ${ }^{1}$
}

\author{
N. Gengler*,2, L. D. Van Vleck†, M. D. MacNeilł, I. Misztal§, and F. A. Pariacote* \\ *Department of Animal Science, University of Nebraska, Lincoln 68583; \\ ${ }^{\dagger}$ Roman L. Hruska US Meat Animal Research Center, ARS, USDA, University of Nebraska,

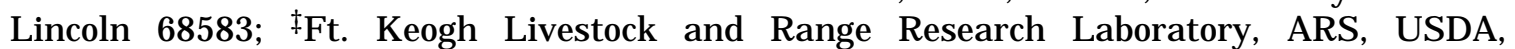 \\ Miles City, MT 59301; and §Department of Animal and Dairy Science, \\ University of Georgia, Athens 30602
}

\begin{abstract}
Two data sets from the USDA Livestock and Range Research Laboratory were analyzed to study dominance variance and the influence of dominance relationships. The first consisted of 4,155 birth weight $(3,884$ weaning weight) records of inbred USDA Line 1 Herefords. The second consisted of 8,065 birth weight (7,380 weaning weight) records from a line-cross experiment with five lines. Two models were used. Both included fixed effects of year-sex of calf and age of dam, and covariates for calving date, inbreeding of animal, and inbreeding of dam. For the second set, additional covariates were line composition and heterozygosity coefficients. Random effects were direct and maternal additive genetic, maternal permanent environment, sire-dam subclass, and residual. Model 1 considered sire-dam subclasses unrelated. Model 2 related sire-dam subclasses with a parental dominance relationship matrix. Variance components were estimated using REML. Differences between
\end{abstract}

estimates with Model 1 and 2 were unimportant except for dominance variance. For the first data set, estimates with Model 2 of relative genetic direct and maternal variances, direct-maternal correlation, permanent environment, and dominance variances for birth weight were $.35, .13,-.02, .03$, and .25 , respectively, and they were $.39, .11, .04, .06$ and .14 for the second data set. For weaning weight, the first data set estimates were $.20, .15,-.37, .19$, and .11, respectively, and they were .16, .20,-.07, .18, and .18 for the second data set. Changes, decreases and increases, in estimates of dominance variances may be due to increased information from relationships and family types other than full-sibs. The assumption of unrelated sire-dam subclasses might not be appropriate for estimation of dominance variance in populations with many dominance relationships among siredam classes.

Key Words: Hereford, Dominance, Growth, Genetic Parameters

\section{Introduction}

Genetic evaluations for beef cattle currently use additive genetic models even if nonadditive effects are not negligible (e.g., Rodriguez-Almeida, 1995). The most important nonadditive effect is probably the dominance effect (e.g., Rodriguez-Almeida, 1995). Setting up the inverted dominance relationship

\footnotetext{
${ }^{1}$ Published as paper no. 11947, J ournal Series, Agric. Res. Div., Univ. of Nebraska, Lincoln 68583-0908.

2The senior author who is Chargé de Recherches of the Fonds National Belge de la Recherche Scientifique, Belgium, wants to acknowledge its financial support. Current address: Unité de Zootechnie, Faculté des Sciences Agronomiques, B-5030 Gembloux, Belgium.

Received March 3, 1997.

Accepted J uly 17, 1997.
}

matrix, $\mathbf{D}^{-1}$, needed in evaluation programs is difficult from a computational point of view when dealing with large data sets. Hoeschele and VanRaden (1991) replaced $\mathbf{D}^{-1}$ with the inverted sire-dam subclass relationship matrix $\mathbf{F}^{-1}$, which does not correspond to the actual dominance covariance structure but to the covariances among sire-dam subclasses that represent the average dominance effect of many hypothetical full-sibs. The variance associated with this effect is one-fourth of the dominance variance. This algorithm provides a way to develop methods to estimate dominance variance for large data sets but at the cost of adding many subclasses that provide ties among existing subclasses. Alternatively, only full-sib contributions might be considered by using uncorrelated sire-dam classes, because those contributions provide the most important information for dominance. However, no studies exist on the influence of the 
Table 1. Descriptive statistics of the weight traits by population

\begin{tabular}{lcrrrr}
\hline \hline $\begin{array}{l}\text { Data set } \\
\text { and trait }\end{array}$ & $\mathrm{n}$ & Mean, kg & SD & Minimum & Maximum \\
\hline Hereford Line 1 (HL 1) & & & & & \\
$\quad$ Birth weight & 4,155 & 35.9 & 4.69 & 18 & 52 \\
$\quad$ Weaning weight & 3,884 & 202.5 & 30.03 & 74 & 314 \\
Hereford line-cross data (H L C) & & & & & \\
$\quad$ Birth weight & 8,065 & 34.5 & 4.73 & 10 & 56 \\
Weaning weight & 7,380 & 192.2 & 29.88 & 68 & 288 \\
\hline
\end{tabular}

parental dominance relationships on estimation of dominance variance. The objective of this study was to evaluate the influence of use or lack of use of dominance relationships on estimation of the variance of dominance genetic effects using parental subclass effects.

\section{Materials and Methods}

\section{Materials}

Two data sets were analyzed. The first data set consisted of 4,155 birth weight (BWT) and 3,884 weaning weight ( WWT, adjusted to $205 \mathrm{~d}$ ) records (Table 1) measured between 1935 and 1989 in the USDA Line 1 Hereford population (HL1). The Hereford Line 1 population was established at the Fort Keogh Livestock and Range Research Laboratory (Miles City, MT) in 1935 to provide inbred seedstock for exploiting heterosis in commercial populations (MacNeil et al., 1992). These data were chosen because many dominance ties exist through the occurrence of the same parental subclasses and because inbreeding occurring in this closed line might interfere with the estimation of dominance variance. Reported inbreeding depression in this population is high (MacNeil et al., 1992), and those authors expected some variance due to dominance effects. Table 2 shows the mean inbreeding coefficients for animals with records and their dams in the present study.

A second data set was obtained from the same research station that consisted of results from a long- time line-cross experiment between Hereford lines ( HLC) measured between 1934 and 1988. The data consisted of 8,065 BWT records and 7,380 WWT records (Table 1 ). Five lines were crossed that started with inbred foundation animals. One of the lines was the USDA Line 1, so some records in HL1 were also in HLC. Also included in HLC were animals of the base population and some immigrants. Animals in HLC were less inbred on average than animals in $\mathrm{HL} l$ even though mean inbreeding coefficients were near $10 \%$ (Table 2).

\section{Methods}

Accounting for inbreeding in dominance analyses for medium to large populations is a computational problem that is not yet solved (e.g., Hoeschele and VanRaden, 1991), even if the algebraic problem has been solved (e.g., J acquard, 1974). The same situation is true for the covariance between additive and dominance effects (J acquard, 1974).

However, there are theoretical reasons why inbred populations showing high inbreeding depression might be interesting candidates for expressing dominance. De Boer and Hoeschele (1993) showed that for a biallelic locus with complete dominance and for favorable gene frequencies that are about .20 or about .80 , large effects of inbreeding depression were linked to high dominance variance.

The usual way to account approximately for inbreeding in the mean and in the variance is to include a fixed effect for inbreeding depression in the model and to allow for inbreeding in construction of the

Table 2. Means and standard deviations of inbreeding in the two data sets for animals with records and their dams

\begin{tabular}{|c|c|c|c|c|c|}
\hline \multirow[b]{2}{*}{ Data set and trait } & \multirow[b]{2}{*}{$\mathrm{n}$} & \multicolumn{2}{|c|}{ Animal } & \multicolumn{2}{|c|}{ Dam } \\
\hline & & Mean, \% & SD & Mean & SD \\
\hline \multicolumn{6}{|c|}{ Hereford Line 1 ( $\mathrm{HL} 1)$} \\
\hline Birth weight & 4,155 & 22.6 & 6.4 & 19.6 & 7.7 \\
\hline Weaning weight & 3,884 & 22.4 & 6.5 & 19.4 & 7.8 \\
\hline \multicolumn{6}{|c|}{ Hereford line-cross data (HLC) } \\
\hline Birth weight & 8,065 & 9.8 & 9.0 & 7.5 & 7.6 \\
\hline Weaning weight & 7,380 & 9.7 & 8.0 & 7.4 & 7.6 \\
\hline
\end{tabular}


inverse of the additive genetic covariance matrix. De Boer and Hoeschele (1993) showed by simulation that this method only slightly reduces accuracies of prediction compared to methods that take exact covariances into account, even with high levels of inbreeding (De Boer and Hoeschele, 1993), such as would be true for the HL1 data.

Both data sets were analyzed using models that accounted for inbreeding depression due to inbreeding of the animal, but also inbreeding of the dam to correct for maternal inbreeding depression because BWT and WWT are considered to be influenced by maternal effects. Additive relationship matrices were constructed using rules defined by Quaas (1976) and account for inbreeding in the relationship matrix. Parental dominance pedigrees (Hoeschele and VanRaden, 1991) were defined as the occurrence of the eight parental subclasses (sire $\times$ maternal grand-sire, sire $\times$ maternal grand-dam, dam $\times$ paternal grandsire, dam $\times$ paternal grand-dam, maternal grand-sire $\times$ paternal grand-sire, maternal grand-sire $\times$ paternal grand-dam, maternal grand-dam $\times$ paternal grandsire, and maternal grand-dam $\times$ paternal grand-dam) of a given sire $\times$ dam class. Coefficients of the inverse of the parental dominance relationship matrix were computed using the method outlined by Hoeschele and VanRaden (1991).

\section{Models}

Variance components were estimated using a modified version of the MTDFREML program (Boldman et al., 1995). In an attempt to avoid stopping at a local maximum of the likelihood function, several restarts were made. The general model was:

$$
\mathbf{y}=\mathbf{X b}+\mathbf{W t}+\mathbf{Z a}+\mathbf{M m}+\mathbf{M p}+\mathbf{P f}+\mathbf{e}
$$

where $\mathbf{y}$ is the vector of BWT or WWT, $\mathbf{b}$ is a vector of fixed unknown year-sex of calf effects and age of dam effects, $\mathbf{t}$ is a vector of fixed unknown linear regression coefficients for the covariates, $\mathbf{a}$ is a vector of random unknown additive direct effects of the animals, $\mathbf{m}$ is a vector of random unknown additive maternal effects of the animals, $\mathbf{p}$ is a vector of random unknown permanent environmental effects of the dam, $\mathbf{f}$ is a vector of random unknown parental(dominance) subclass effects, $\mathbf{e}$ is a vector of random unknown uncorrelated residual effects, and $\mathbf{X}, \mathbf{W}, \mathbf{Z}, \mathbf{M}$, and $\mathbf{P}$ are known matrices linking $\mathbf{y}$ with $\mathbf{b}, \mathbf{t}, \mathbf{a}, \mathbf{m}, \mathbf{p}$, and $\mathbf{f}$. The $\mathbf{X}, \mathbf{Z}, \mathbf{M}$, and $\mathbf{P}$ matrices and the $\mathbf{b}, \mathbf{a}, \mathbf{m}, \mathbf{p}, \mathbf{f}$, and e vectors are defined the same way for both data sets; however, $\mathbf{W}$ and $\mathbf{t}$ are different for HLC because of covariates for line and heterozygosity effects.

For the first data set covariates were calving day within calving season expressed as day in the year, inbreeding coefficient of the animal, and inbreeding coefficient of the dam. Inbreeding covariates were used in the model to get correct estimates of the underlying base population dominance variance as explained by DeBoer and Hoeschele (1993).

For the second data set, additional covariates were for line or group contribution (five lines plus groups for base population and immigrants) to account for line differences. Covariates for heterozygosity were also included to account for potential heterosis occurring in line-cross animals. Heterosis was computed with the usual method as $1-\mathbf{c}_{s} \mathbf{c}_{d}$ where $\mathbf{c}_{\mathrm{s}}$ and $\mathbf{c}_{\mathrm{d}}$ are vectors of fractions of breed compositions for sire and dam of the individual. To simplify the model, covariates for line and heterozygosity effects were limited to direct contributions and were not used for maternal line and heterozygosity effects. There were two reasons to do this. First, the maternal and direct covariates would have been highly confounded. Second, earlier research showed that the covariates for line and heterozygosity effects were small (Pariacote et al., unpublished data). This result was expected because the lines involved were all Herefords, and heterosis is expected to be less within than between breeds. The assumption of a common heterosis effect for all line-crosses was made for two reasons. All crosses were between animals from the same breed. Also, consideration of different heterosis effects would have resulted in 21 heterosis effects with corresponding difficulty in estimation of these coefficients. The estimation of all these coefficients would have been a problem, even if the eventual effect of this simplification needs to be acknowledged.

Covariances between records of full-sibs $x$ and $y$ can be approximated as: $\operatorname{cov}(x, y)=.5 a^{2}+m^{2}+c^{2}+.25 d^{2}+$ $.25 a a^{2}+.125 a d^{2}+r$, where $a^{2}$ is additive direct genetic variance, $\mathrm{m}^{2}$ is additive maternal genetic variance, $c^{2}$ is maternal permanent environmental variance, $d^{2}$ is dominance genetic variance, $a a^{2}$ is additive by additive genetic variance, and $\mathrm{ad}^{2}$ is additive by dominance variance. Other variances, and covariances among genetic effects, can theoretically be considered and are indicated as $r$. The general Model [1] used takes the first four elements of $\operatorname{cov}(x, y)$ and the covariance between additive direct and maternal genetic effects into account. Dominance variance was estimated as parental variance, $\mathrm{f}^{2}$. Separation of $\mathrm{m}^{2}$ and $c^{2}$ is possible through the introduction of the additive relationship matrix relating maternal effects. For estimation of $d^{2}$ as $4 * f^{2}$ real parental dominance effects and confounded parental effects such as $c^{2}, a^{2}$ or $\mathrm{ad}^{2}$ need to be separated. To illustrate any differences between models with parental subclass effects and parental dominance subclass effects, the two models used differed only in the assumption about $\operatorname{Var}(\mathbf{f})$. For Model 1, $\operatorname{Var}(\mathbf{f})$ was assumed to be $\mathbf{I f}^{2}$ (i.e., parental subclasses were assumed unrelated). For Model 2, $\operatorname{Var}(\mathbf{f})$ was assumed to be $\mathbf{F f}^{2}$, where $\mathbf{F}$ is the parental dominance subclass relationship matrix as defined by Hoeschele and VanRaden (1991). The algorithm described by Hoeschele and 
VanRaden (1991) was used to establish the dominance pedigree limiting recurrence to one round, because this was considered sufficient to give nearly full dominance relationships among parental subclasses.

Estimates with Models 1 and 2 were then used to compare the parental subclass variances obtained with or without considering dominance relationships. The comparisons were not made with the full dominance matrix as the objective was to test the use of unrelated sire-dam or sire-maternal grand sire classes for estimation of dominance variance (e.g., Brade and Groeneveld, 1996) compared with the method described by Hoeschele and VanRaden (1991).

\section{Approximate Standard Errors}

Approximate standard errors of results were obtained using the method described by VanRaden et al. (1992) adapted for models with maternal effects. This method is based on the definition of covariances between individuals. These covariance components can be transformed to between- and within-family variances in which family types are defined as full-sib, parent-progeny, half-sib, and three-quarter-sib families using variance estimates obtained or assumed. Families were subdivided into maternal and paternal family types because maternal effects were in these models. Variances of quadratic forms associated with family types were obtained using number of ideal size families in data sets and the variances of the withinand between-family variances. Ideal family size as defined by VanRaden et al. (1992) is the most informative family size. For every real family, the equivalent was computed and then summed to get the number of families of ideal size. The variances and covariances among the family type variances were then back-transformed to an approximate variancecovariance matrix of the parameter estimates. The diagonal elements were considered the squared standard errors of the variance component estimates. This method has the advantage of simplicity and ease of use but has several shortcomings and disadvantages. The method considers several times any animal that appears in several families and additional information from relationships between families cannot be taken into account. Therefore, sources of information are not independent. All computations were done assuming a balanced case, whereas real data never fit this condition. The method does not account for the estimation of fixed effects. Therefore, the estimates are only approximate and are basically lowerbound maximum likelihood type standard errors. Despite these objections, this method was used as a way to assess the precision of the estimates and therefore of the differences in estimates of variances for Model 1 and Model 2.

\section{Results and Discussion}

\section{Descriptive Statistics}

Both data sets were small, and absolute results for estimates of dominance variance should be considered cautiously. The objective was to consider changes in estimates rather than absolute values of these estimates to illustrate the potential importance of the dominance relationship matrix.

Mean birth weights were similar in both data sets (35.9 and $34.5 \mathrm{~kg}$; Table 1), whereas WWT was greater for the HL 1 animals $(202.5 \mathrm{~kg})$ compared to 192.2 for HLC animals (Table 2). Standard deviations were similar for both data sets for BWT and WWT. Extreme values that were observed for WWT could be explained by the variable climate in Montana.

Both data sets included animals with considerable inbreeding, high in HL1 and moderate in HLC (Table 2 ). Average level of inbreeding of dams was always less than average inbreeding of animals. Standard deviations of inbreeding coefficients were similar, showing a high variability in inbreeding in both populations over time.

\section{Contributions to Matrix of Family Variances}

Estimation of standard errors required the matrix of contributions of genetic effects to family variances. Table 3 shows this matrix for Model 2. For Model 1, only sire $\times$ dam interactions were considered, and therefore contributions through three-quarter-sibs were ignored. This method is approximate and does not reflect the total gain in information by using Model 2 rather than Model 1 .

\section{Variance Components}

Phenotypic Variance. Table 4 shows the estimates of phenotypic variance for Models 1 and 2 for both data sets. Estimated phenotypic variances were always slightly less for Model 2.

Additive Effects. Relative estimates of variance due to additive direct and maternal genetic effects are given in Table 4. Changes from Model 1 and Model 2 were small for additive effects. This result was expected as reported by Misztal et al. (1997) and due to the relative weakness of dominance information compared to other random effects. Estimates of genetic variance due to additive direct effects for BWT for the HL1 data were similar to previous estimates reported by MacNeil et al. (1992), who used the same data without modeling dominance effects. Relative additive maternal genetic variance was less than estimates reported by these authors, and genetic correlation between direct and maternal genetic effects was also smaller. These differences may be because their model did not include a permanent environmental effect of the dam. Estimates for the HLC data set were similar to HL1 for BWT showing only small differences in 
Table 3. Contribution of additive direct genetic, additive maternal genetic, permanent environment of the dam, dominance genetic, and residual effects to variances within (w) and between (f) families by family type

\begin{tabular}{|c|c|c|c|c|c|c|}
\hline Family type & Variance & Direct & Maternal & Permanent & Dominance & Residual \\
\hline Full-sibs & $\begin{array}{l}w \\
f\end{array}$ & $\begin{array}{l}.5 \\
.5\end{array}$ & $\begin{array}{l}0 \\
1\end{array}$ & $\begin{array}{l}0 \\
1\end{array}$ & $\begin{array}{l}.75 \\
.25\end{array}$ & $\begin{array}{l}1 \\
0\end{array}$ \\
\hline \multicolumn{7}{|c|}{ Parent progeny } \\
\hline Animal-sire & $\begin{array}{l}w \\
f\end{array}$ & $\begin{array}{l}.5 \\
.5\end{array}$ & $\begin{array}{l}1 \\
0\end{array}$ & $\begin{array}{l}1 \\
0\end{array}$ & $\begin{array}{l}1 \\
0\end{array}$ & $\begin{array}{l}1 \\
0\end{array}$ \\
\hline Animal-dam & $\begin{array}{l}w \\
f\end{array}$ & $\begin{array}{l}.5 \\
.5\end{array}$ & $\begin{array}{l}.5 \\
.5\end{array}$ & $\begin{array}{l}1 \\
0\end{array}$ & $\begin{array}{l}1 \\
0\end{array}$ & $\begin{array}{l}1 \\
0\end{array}$ \\
\hline \multicolumn{7}{|l|}{ Half-sibs } \\
\hline Paternal & $\begin{array}{l}w \\
f\end{array}$ & $\begin{array}{l}.75 \\
.25\end{array}$ & $\begin{array}{l}1 \\
0\end{array}$ & $\begin{array}{l}1 \\
0\end{array}$ & $\begin{array}{l}1 \\
0\end{array}$ & $\begin{array}{l}1 \\
0\end{array}$ \\
\hline Maternal & $\begin{array}{l}w \\
f\end{array}$ & $\begin{array}{l}.75 \\
.25\end{array}$ & $\begin{array}{l}0 \\
1\end{array}$ & $\begin{array}{l}0 \\
1\end{array}$ & $\begin{array}{l}1 \\
0\end{array}$ & $\begin{array}{l}1 \\
0\end{array}$ \\
\hline \multicolumn{7}{|c|}{ Three-quarter-sibs } \\
\hline Sire-MGS ${ }^{a}$ & $\begin{array}{l}w \\
f\end{array}$ & $\begin{array}{l}.6875 \\
.3125\end{array}$ & $\begin{array}{l}.75 \\
.25\end{array}$ & $\begin{array}{l}1 \\
0\end{array}$ & $\begin{array}{l}.9375 \\
.0625\end{array}$ & $\begin{array}{l}1 \\
0\end{array}$ \\
\hline Sire-MGD ${ }^{b}$ & $\begin{array}{l}w \\
f\end{array}$ & $\begin{array}{l}.6875 \\
.3125\end{array}$ & $\begin{array}{l}.75 \\
.25\end{array}$ & $\begin{array}{l}1 \\
0\end{array}$ & $\begin{array}{l}.9375 \\
.0625\end{array}$ & $\begin{array}{l}1 \\
0\end{array}$ \\
\hline Dam-PGS & $\begin{array}{l}w \\
f\end{array}$ & $\begin{array}{l}.6875 \\
.3125\end{array}$ & $\begin{array}{l}0 \\
1\end{array}$ & $\begin{array}{l}0 \\
1\end{array}$ & $\begin{array}{l}.9375 \\
.0625\end{array}$ & $\begin{array}{l}1 \\
0\end{array}$ \\
\hline Dam-PGD ${ }^{d}$ & $\begin{array}{l}w \\
f\end{array}$ & $\begin{array}{l}.6875 \\
.3125\end{array}$ & $\begin{array}{l}0 \\
1\end{array}$ & $\begin{array}{l}0 \\
1\end{array}$ & $\begin{array}{l}.9375 \\
.0625\end{array}$ & $\begin{array}{l}1 \\
0\end{array}$ \\
\hline
\end{tabular}

${ }^{\mathrm{a}} \mathrm{MGS}=$ maternal grand-sire.

bMGD = maternal grand-dam .

CPGS = paternal grand-sire.

dPGD $=$ paternal grand-dam.

relative variances and a small positive instead of a small negative genetic correlation between additive direct and maternal genetic effects.

For WWT, important differences were observed between estimates from HLI and HLC data. Variances of genetic maternal effects were slightly larger for HLC than for HL1, and variances of additive direct genetic effects were slightly larger for HL 1 than for
HLC; the most important difference was the moderate negative genetic correlation between direct and maternal additive genetic effects in HLI (-.37 and -.38) compared to the estimates for HLC ( -.10 and -.07).

Estimates of relative additive genetic variances were in the range reported by Rodriguez-Almeida et al. (1995), and with maternal genetic variance nearly equal to direct additive genetic variance.

Table 4. Estimates of relative variance components and genetic correlations with approximate standard errors

\begin{tabular}{|c|c|c|c|c|c|c|c|c|c|c|c|}
\hline \multirow{2}{*}{$\begin{array}{l}\text { Data set } \\
\text { and trait }\end{array}$} & \multirow[b]{2}{*}{ Model } & \multicolumn{10}{|c|}{ Relative variance components ${ }^{a}$} \\
\hline & & $a^{2}$ & $( \pm S E)$ & $\mathrm{r}(\mathrm{am})$ & $\mathrm{m}^{2}$ & $( \pm S E)$ & $c^{2}$ & $( \pm S E)$ & $d^{2}$ & $( \pm S E)$ & $\mathrm{PV}^{\mathrm{b}}$ \\
\hline \multicolumn{12}{|c|}{ Hereford line 1 (HL 1$)$} \\
\hline $\mathrm{BWT} \mathrm{T}^{\mathrm{C}}$ & $\begin{array}{l}1 \\
2\end{array}$ & $\begin{array}{l}.35 \\
.35\end{array}$ & $\begin{array}{l}( \pm .07) \\
( \pm .07)\end{array}$ & $\begin{array}{l}-.05 \\
-.02\end{array}$ & $\begin{array}{l}.13 \\
.13\end{array}$ & $\begin{array}{l}( \pm .05) \\
( \pm .05)\end{array}$ & $\begin{array}{l}.03 \\
.03\end{array}$ & $\begin{array}{l}( \pm .04) \\
( \pm .04)\end{array}$ & $\begin{array}{l}.37 \\
.25\end{array}$ & $\begin{array}{l}( \pm .17) \\
( \pm .16)\end{array}$ & $\begin{array}{l}17.96 \\
17.62\end{array}$ \\
\hline WWT $T^{d}$ & $\begin{array}{l}1 \\
2\end{array}$ & $\begin{array}{l}.20 \\
.20\end{array}$ & $\begin{array}{l}( \pm .09) \\
( \pm .09)\end{array}$ & $\begin{array}{l}-.38 \\
-.37\end{array}$ & $\begin{array}{l}.16 \\
.15\end{array}$ & $\begin{array}{l}( \pm .06) \\
( \pm .06)\end{array}$ & $\begin{array}{l}.19 \\
.19\end{array}$ & $\begin{array}{l}( \pm .06) \\
( \pm .06)\end{array}$ & $\begin{array}{l}.00 \\
.11\end{array}$ & $\begin{array}{l}( \pm .19) \\
( \pm .18)\end{array}$ & $\begin{array}{l}529.7 \\
524.6\end{array}$ \\
\hline \multicolumn{12}{|c|}{ Hereford line cross data ( $H L C)$} \\
\hline $\mathrm{BWT}^{\mathrm{c}}$ & $\begin{array}{l}1 \\
2\end{array}$ & $\begin{array}{l}.39 \\
.39\end{array}$ & $\begin{array}{l}( \pm .05) \\
( \pm .05)\end{array}$ & $\begin{array}{l}.01 \\
.04\end{array}$ & $\begin{array}{l}.11 \\
.11\end{array}$ & $\begin{array}{l}( \pm .03) \\
( \pm .03)\end{array}$ & $\begin{array}{l}.05 \\
.06\end{array}$ & $\begin{array}{l}( \pm .03) \\
( \pm .03)\end{array}$ & $\begin{array}{l}.07 \\
.14\end{array}$ & $\begin{array}{l}( \pm .12) \\
( \pm .11)\end{array}$ & $\begin{array}{l}17.85 \\
17.68\end{array}$ \\
\hline$W W T^{d}$ & $\begin{array}{l}1 \\
2\end{array}$ & $\begin{array}{l}.16 \\
.16\end{array}$ & $\begin{array}{l}( \pm .06) \\
( \pm .06)\end{array}$ & $\begin{array}{l}-.10 \\
-.07\end{array}$ & $\begin{array}{l}.21 \\
.20\end{array}$ & $\begin{array}{l}( \pm .05) \\
( \pm .04)\end{array}$ & $\begin{array}{l}.18 \\
.18\end{array}$ & $\begin{array}{l}( \pm .04) \\
( \pm .04)\end{array}$ & $\begin{array}{l}.01 \\
.18\end{array}$ & $\begin{array}{l}( \pm .12) \\
( \pm .11)\end{array}$ & $\begin{array}{l}521.4 \\
514.5\end{array}$ \\
\hline
\end{tabular}

$\mathrm{a}^{2}=$ direct heritability, $\mathrm{r}(\mathrm{am})=$ correlation between direct and maternal effects, $\mathrm{m}^{2}=$ maternal heritability, $\mathrm{c}^{2}=$ relative permanent environment of the dam variance, $d^{2}=$ relative dominance variance.

bPV = phenotypic variance in $\mathrm{kg}^{2}$.

'BWT = birth weight.

dWWT = weaning weight. 
Permanent Environmental Effects of the Dam. Some analyses have found this effect rather unimportant (e.g., Rodriguez-Almeida et al., 1995), a result consistent here only for BWT, where for both populations the relative variances were less than or equal to .06. For WWT in both populations, the variance of nongenetic effects of the dams was greater than ( $H L 1)$ or nearly equal ( $H L C)$ to that for genetic maternal effects.

Dominance Effects. Estimates of dominance variances reported in Table 4 are defined as four times the parental subclass variance. The estimate for BWT for HL1 was larger for Model 1 (.37, parental subclass model, classes considered unrelated) than for Model 2 (.25, parental subclass model with complete dominance relationships). Approximate standard errors for these estimates were large. Much larger data sets would be required to reduce the standard errors to the level of standard errors of the other variances (Misztal, 1997), even though the data sets, HL1 and HLC, have more dominance relationships than field data sets. The estimate for Model 2, which can be considered the more likely dominance estimate, had a confidence range, defined as estimate plus or minus one standard error, that did not include zero.

For the HLC population, estimates of dominance variance were less for BWT than for the HL1 population. Difference between Model 1 and Model 2 was also important with the estimate increasing from .07 for Model 1 to .14 for Model 2. The relative change in estimate of dominance variance was about the same in both populations, but in a different direction. The estimate plus and minus the standard error did not include zero for Model 2.

For WWT, the pattern of estimates was different. In the HL1 population, Model 1 showed an estimate of apparent relative variance due to dominance effects of zero, but with Model 2 the estimate was .11. The influence of the dominance relationship matrix seemed to be important. Standard errors were large (.18 and .19). A similar pattern was observed for the HLC data with an increase in the estimate from .01 to .18 due to the introduction of the relationship matrix (Model 2) for HLC. The range of this estimate (Model 2 ), defined as the estimate plus or minus the standard error, did not include zero.

There are at least three possible reasons for the changes in estimates of dominance variance with the complete dominance relationships that were observed. First, changes may be due to sampling errors. Second, changes may be due to the fact that the apparent dominance variance estimate for Model 1 may contain other than dominance variances. Third, the differences may also be a result of the increased amount of dominance information from the use of the dominance relationship matrix relating full-sib families to each other and including information from other family types. The data used were identical, and Models 1 and
2 differed only by $\operatorname{Var}(\mathbf{f})$; thus, the first reason may have only limited influence. If the second reason had a major impact, apparent dominance should have been reduced and redistributed to other variances. But all other genetic variances and covariances, as well as the variance of permanent environmental effects of the dam, were stable, and nearly all changes occurred between residual and apparent dominance variance components. Only for BWT for HLI was apparent dominance variance reduced, indicating possible confounding with higher-order genetic effects. This confounding should be less for Model 2 because it accounts for most dominance (co)variances. The third reason might be considered to be the most likely origin of the differences.

The simple idea to use unrelated sire $\times$ dam or sire $\times$ maternal grand-sire classes is not new (e.g., Allaire and Henderson, 1965) and is still used (e.g., Brade and Groeneveld, 1996). These results show that this simplification might not be a good option, even though most dominance information seems to be from sire $x$ dam classes or from sire $\times$ maternal grandsire classes for dairy cattle. The variance of apparent dominance effects obtained through the use of unrelated sire $x$ dam subclasses may be confounded with variances of higher order so that information coming through the dominance relationship matrix, relating sire $\times$ dam classes and including other family types, may affect the estimates obtained of dominance genetic effects.

\section{Implications}

The results indicate that dominance effects may exist for birth weight and weaning weight in Hereford cattle. Standard errors of the estimates, however, were large. Studies involving more animals are needed. The main objective of this study, however, was to show the influence that the use of the parental dominance relationship matrix may have. Estimates of dominance variances from all four analyses changed considerably, going from a simple model with unrelated sire $\times$ dam classes to a model with complete parental dominance relationships. The short-cut method, therefore, may not be useful for all dominance studies, even if most dominance information seems to be from sire $x$ dam classes. A similar effect of the dominance relationship matrix might be expected for genetic evaluation models that include dominance genetic effects.

\section{Literature Cited}

Allaire, F. R., and C. R. Henderson. 1965. Specific combining abilities among dairy sires. J. Dairy Sci. 48:1096-1100.

Boldman, K. G., L. A. Kriese, L. D. Van Vleck, C. P. Van Tassell, and S. D. Kachman. 1995. A manual for use of MTDFREML [Draft]. USDA, ARS, US Meat Animal Research Center, Clay Center, NE. 
Brade, W., and E. Groeneveld. 1996. Importance of special combining ability in dairy breeding. Presented at the 47th Mtg. of the EAAP, Lillehammer, Norway, August 26-29, 1996.

De Boer, I.J .M., and I. Hoeschele. 1993. Genetic evaluation methods for populations with dominance and inbreeding. Theor. Appl. Genet. 86:245-258.

Hoeschele, I., and P. M. VanRaden. 1991. Rapid inversion of dominance relationship matrices for noninbred populations by including sire by dam subclass effects. J . Dairy Sci. 74:557-569.

J acquard, A. 1974. The Genetic Structure of Populations. SpringerVerlag, New York.

MacNeil, M. D., J . J . Urick, S. Newman, and B. W. Knapp. 1992. Selection for postweaning growth in inbred Hereford cattle: The Fort Keogh, Montana Line 1 example. J . Anim. Sci. 70:723-733.
Misztal, I. 1997. Estimation of variance components with large-scale dominance models. J. Dairy Sci. 80:965-974.

Misztal, I., T. J. Lawlor, and R. L. Fernando. 1997. Dominance models with Method R for stature of Holsteins. J . Dairy Sci. 80: 975-978.

Quaas, R. L. 1976. Computing the diagonal elements and inverse of a large numerator relationship matrix. Biometrics 32:949-953.

Rodriguez-Almeida, F. A., L. D. Van Vleck, R. L. Willham, and S. L. Northcutt. 1995. Estimation of non-additive genetic variances in three synthetic lines of beef cattle using an animal model. J . Anim. Sci. 73:1002-1011.

VanRaden, P. M., T. J . Lawlor, T. H. Short, and I. Hoeschele. 1992. Use of reproductive technology to estimate variances and predict effects of gene interactions. J . Dairy Sci. 75:2892-2901. 